\title{
A review of BF-200 ALA for the photodynamic treatment of mild-to-moderate actinic keratosis
}

\author{
Uwe Reinhold ${ }^{*}, 1$ \\ ${ }^{1}$ Dermatological Center Bonn Friedensplatz, Bonn, Germany \\ * Author for correspondence: u.reinhold@derma-bonn.de
}

BF-200 ALA is a combination of a nanoscale-lipid vesicle formulation and the prodrug 5-aminolevulinic acid (5-ALA). The nanoemulsion stabilizes the prodrug and enhances its penetration through the stratum corneum. It has shown excellent therapeutic results in both lesion and field-directed photodynamic therapy of actinic keratosis (AK). AK is an early form of epidermal neoplasia and a precursor of invasive cutaneous squamous cell carcinoma. It is characterized by the combination of visible neoplastic lesions and surrounding tissue also harboring tumorigenic UV-induced mutations: a concept called field cancerization. A selective, field-directed treatment is ideal to meet the requirements of field change. Here, we review the clinical data on BF-200 ALA for AK along with a summary of molecular mechanisms and future perspectives.

First draft submitted: 29 May 2017; Accepted for publication: 24 July 2017; Published online: 14 August 2017

Keywords: 5-ALA • actinic keratosis • BF-200 ALA • daylight PDT (DL-PDT) • field cancerization • field-directed treatment • light source $\bullet$ light spectrum • nanoemulsion • photodynamic therapy (PDT) • simulated daylight-PDT (SDL-PDT)

Actinic keratosis (AK), also known as solar keratosis, is caused by chronic exposure to sunlight or other ultraviolet light sources [1,2] and may progress to invasive squamous cell carcinoma (SCC) [3]. It is the most common lesion with malignant potential to arise on the skin. AK is mostly seen in Caucasians in skin areas that have extensive sun exposure throughout their lives [4]. Epidemiological data show a high occurrence rate of AK. Regions with higher ultraviolet exposure have a higher prevalence of AK. For the USA, the prevalence was estimated to range from 11 to $26 \%$, while in Australia it ranged from 40 to $60 \%$. In Europe, a prevalence of $15 \%$ in men and $6 \%$ in women has been documented [5]. Over the age of 70 years, $34 \%$ of men and $18 \%$ of women were found to have actinic keratotic lesions [6]. Next to fair skin type, an advanced age and lifelong sun exposure immunosuppression/-deficiency plays another important risk factor [5].

Mostly, AK develops slowly and early in the disease process, they may disappear only to reappear later. Recurrence of the disease may include partial elimination of the initial lesion, subclinical lesion progression to visible status, or development of new lesions [7]. On top of this, an AK may progress to invasive SCC, the second-most common form of skin cancer $[8,9]$. The actual percentage of progress to invasive SCC remains unknown, and estimates vary from 5 to $20 \%$ within 10 to 25 years with reported annual transformation rates varying greatly from as low as $0.25 \%$ to as high as $16 \%$ [10]. The regression rate for a single untreated lesion is 15 to $63 \%$ after a year; recurrence rates range from 15 to $53 \%$ [11]. In general patients develop multiple AKs in one area and predicting which course each individual lesion will follow is impossible. Nonetheless, AK lesions are reliable markers for patients who are most predisposed to developing invasive SCC [4,12-13].

AK lesions typically appear in areas most frequently exposed to the sun such as the face, back of the hands, or bald scalp; $75 \%$ of lesions are found on the head, neck and forearms [14]. The lesions vary in appearance as well as size and can include erythematous scaly macules, rough pigmented patches and hyperkeratotic skin horns. Most lesions have the same color like the surrounding skin, but some are present as pink, red or brownish lesions. Since most AKs are found in areas of chronically sun-exposed skin, including scalp, face, ears and hands, those lesions are 
often associated with signs of chronic sun damage, for example, dyschromia, elastosis and wrinkles. Often, multiple lesions are found in the same area [15,16].

Clinically, AKs are classified by the Olsen grading scheme [17]: AK grade I is slightly palpable (better felt than seen), AK grade II is visible and moderately thick (easily felt and seen), AK grade III is thick and hyperkeratotic (obvious actinic keratosis, felt and seen). Furthermore, AKs are histologically classified based on the Roewert-Huber histological classification system. This method analyzes the extent of atypical keratinocytes (AK I-III) [18]. The two systems have recently been shown not to correlate [19]. An objective assessment of AKs for scoring their severity on the head has been developed and is described in the actinic keratosis and severity index [20]. This new assessment tool could be useful for AK classification and management in dermatological practice.

The pathogenesis of AK is mainly related to chronic UV radiation, especially UVB radiation. UVB radiation can induce DNA damage, leading to pyrimidine dimers followed by DNA mutations. The most prominent DNA mutations in this context are mutations in the tumor suppressor gene TP53, leading to a dysregulated p 53 pathway [21]. As a consequence, keratinocytes clonally expand and can further progress into invasive SCCs [22].

As visible AK lesions predominantly arise in chronically sun-exposed areas, it is conceivable that distinct areas of the skin (e.g., bald scalps or foreheads) are affected and contain mutated keratinocytes that expand clonally and spread throughout the area [23]. This is strongly related to Slaughter's concept of field cancerization, first published in 1953 [24], and wisely revisited from a modern molecular perspective by Braakhuis et al. [25]. According to this concept of field change, the clinically inconspicuous tissue between visible AK lesions is in all likelihood interspersed with UV-mutated clones. These can potentially sustain and aggravate the disease state, if only visible lesions are treated [26,27]. In addition, it has been shown that mild AKs (grade I) are the most common lesion associated with invasive SCC $[12,13]$. Since there are no defined clinical indicators or specific genetic markers to predict progression to SCC, the expert opinion is to administer AK treatment in a field-directed manner in all patients to prevent invasive SCCs [28]. Approximately 65\% of all primary SCCs develop from lesions previously diagnosed as AK [29]. The remainders most likely develop from subclinical AK lesions in cancerized fields [12]. Thus, in order to prevent disease progression, it is strongly advised to treat AK with all diligence independent of severity [16].

\section{Photodynamic therapy for actinic keratosis}

The high prevalence, increasing incidence and risk of progression to cancerous lesions imply that prevention and timely treatment of AK offer opportunities to reduce the risk of cancer development and cost [30,31]. Ideally, a therapy for AK would have the following characteristics: high efficacy, high clearance rates, reduction in the need for re-treatment by low recurrence rates (currently 25 to $75 \%$ of patients need to be re-treated at 12 months), low incidence of adverse events and a simplified treatment regimen [32]. As general means of prevention, all AK patients should be made aware of the detrimental effects of excessive UV exposure and advised to adapt their behavior accordingly. Even if visible lesions are cleared by the treatments, patients still should limit sun exposure and use sunscreens [16].

The appropriate treatment for AK is generally chosen based on the number and location of the lesions or field change present. Additional variables to consider include persistence of the lesions, age of the patient, history of skin cancer and tolerability of the treatment modality $[10,33,34]$. Treatment options belong to two broad categories: surgical destruction of the lesions (e.g., using cryotherapy or curettage with or without electrosurgery, laser) and topical therapies (e.g., 5-fluorouracil cream, imiquimod cream, ingenol mebutate, diclofenac gel and photodynamic therapy (PDT)). Surgical destruction is restricted to limited areas and frequently associated with a flawed cosmetic result [33]. Topical pharmaceutical therapy allows the treatment of extended areas with many AK lesions. The advantage of field-directed treatment is the treatment of potential subclinical lesions, as described above. In contrast, lesion-directed treatment addresses only visible and palpable AK lesions [10,33,34].

Regardless of severity, the primary goal of AK treatment is to achieve complete clearance of all visible and subclinical lesions (i.e., cancerized fields) per individual patient [35]. Oncology and dermatology clinical guidelines recommend early and effective treatment $[16,34,36]$.

In clinical studies, PDT with aminolevulinic acid (ALA) has been shown to achieve good results within a short time and a maximum of two treatment sessions $[37,38]$. Several ALA-based topical medications have been used, mostly differing in regard to additional chemical modifications, other vehicle compositions, types of administration or the use of other wavelengths. Examples are methyl-aminolevulinate (MAL), ALA-compounding formulations, ALA-patches, ALA-solutions and the ALA-nanoemulsion (BF-200 ALA). 
The relative efficacy of ten different treatment modalities has been analyzed in a European network metaanalysis (NMA) [37]. Study selection was based on the Cochrane systematic search and review for actinic keratosis treatments [38]. Studies with the primary outcome measure 'complete patient clearance' were considered and included. The included drugs comprised BF-200 ALA, ALA-patch, MAL, three modalities of imiquimod (3.75$5.0 \%$ ), cryotherapy, $3 \%$ diclofenac in $2.5 \%$ hyaluronic acid, $0.5 \% 5$-FU and ingenol mebutate. The metaanalysis indicates that all treatment options were significantly superior compared with placebo, with BF-200 ALA photodynamic therapy being the most efficient treatment [37]. This finding is corroborated by the findings of Dirschka et al. who studied and compared 1 year follow-up treatments for selected AK treatment modalities and, among those, found BF-200 ALA to show the most sustainable efficacy [39]. While all modalities are approved for lesion-directed treatment, some are additionally approved for field-directed treatment. Among the PDT drugs, only BF-200 ALA is approved for the field directed treatment of AKs, in other words, field cancerization [40,41]. Since the NMA was performed from a European clinical practice perspective, the ALA stick (20\% solution) was not included in the analysis. Comparison of the ALA stick with BF-200 ALA based on their corresponding US prescribing information reveals complete patient clearance response of $63-69 \%$ for the ALA stick and $84-91 \%$ for BF-200 ALA [41,42].

Photodynamic therapy has been widely studied and several approaches have been used for treatment [43]. In general there are three requirements for PDT: a photosensitizer, molecular oxygen and light of a specific wavelength. For dermatological PDT usually a prodrug is topically applied to the skin, which is then converted by the cells, especially by neoplastic cells, into the actual photosensitizer [44,45]. One prodrug which has been extensively studied is 5-aminolevulinic acid (5-ALA), an endogenous precursor for the heme biosynthesis [46].

The molecular mechanism of action is based on the cellular ALA uptake, synthesis and accumulation of the photosensitizer PpIX, which can be excited by light of specific wavelengths leading to the formation of reactive oxygen species, upon the presence of oxygen [47]. These reactive oxygen species can initiate cell death in the form of apoptosis, necrosis and autophagy [48]. In healthy cells, heme negatively regulates the ALA-synthase, thereby leading to a decreased synthesis of endogenous ALA, which then limits the turnover rates to PpIX [49,50].

An important factor is the selectivity of exogenous ALA for neoplastic cells compared with healthy cells. This selectivity can be attributed to different mechanisms resulting from alterations in cellular ALA uptake, heme biosynthetic pathway, mitochondrial functions or drug resistance transporters [51]. It has been shown that neoplastic cells often exhibit a decreased ferrochelatase activity which results in a reduced conversion to heme and therefore leading to accumulation of PpIX [51]. Moreover, neoplastic cells often show an enhanced activity of several enzymes such as ALA dehydratase, uroporphyrinogen decarboxylase or porphobilinogen deaminase leading to an enhanced PpIX production [52]. Another possible explanation for the increased accumulation in neoplastic cells could be the altered ALA or porphyrin uptake or decreased PpIX efflux mechanisms [51].

From a pharmaceutical perspective, besides selectivity, also epidermal penetration and stability of the prodrug and its vehicle determine the efficacy of ALA-PDT [19].

\section{Enhancing PDT with nanoemulsion technology}

Two factors that are essential for ALA-based PDT are stability and epidermal penetration of the prodrug [53]. Stability of topical ALA preparations is critical, as ALA has been shown to be prone to degradation to 2.5-(betacarboxyethyl)-dihydropyrazine and 2.5-(beta-carboxyethyl)-pyrazine in aqueous solutions [54]. This, in principal irreversible chemical reaction driving this degradation, is a head-to-head condensation of two ALA molecules at their $\mathrm{C} 1$ carbon atoms, in other words, the acid groups [54]. The resulting molecule is useless for further biological metabolism. As a consequence, classical ALA preparations such as compounded ALA in topical creams, ointments and gels have a very limited stability and have to be used within hours to days after production [55]. Several strategies were implemented to circumvent this accelerated degradation process. A well described approach is the chemical stabilization of ALA by esterification. A series of investigations over 20 years ago led to the production of various ALA esters [56]. These molecules, for example ALA methyl ester (MAL), are less prone to the abovementioned degradation process [54]. The drawback of this approach lies in the biological need to have the ester cleaved by cellular enzymes before ALA can enter the heme biosynthetic pathway. Thus, some ALA esters, especially MAL, have been shown to induce less PpIX compared with ALA after the same incubation time [57-59]. Additionally, the concentration of short-chained ALA-esters (C1-C3), which is required to induce half-maximal PpIX accumulation, was clearly higher in several cell lines than the corresponding concentration of ALA [56]. Increasing ALA-ester concentration may of course compensate for this. Longer chain ALA esters, such as hexyl-ALA (C6), display a 


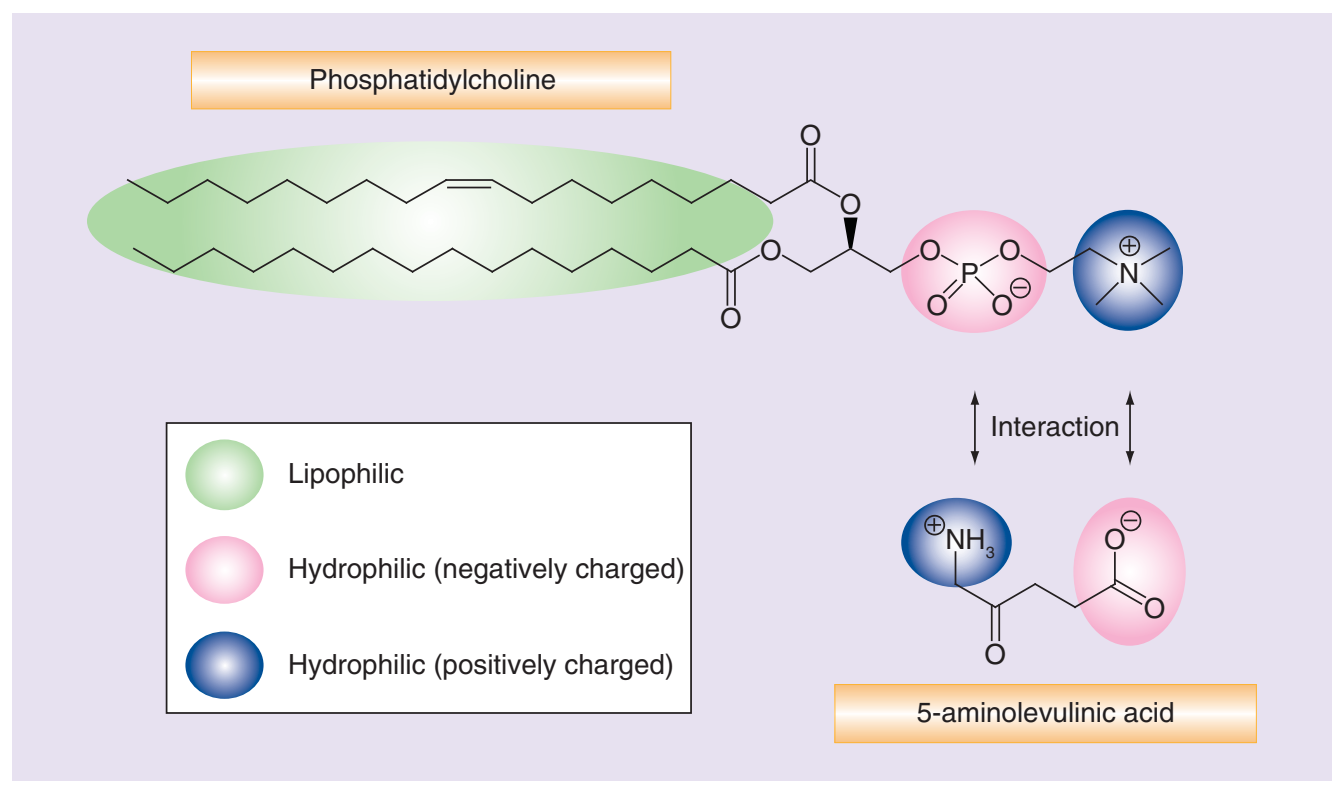

Figure 1. Postulated interaction model between 5-aminolevulinic acid and the phospholipids of the nanoemulsion. The green sphere depicts lipophilic moiety, the red sphere negatively charged functional group and the blue positively charged functional group. As seen in this figure, polar moieties of phosphatidylcholine may have interactions with the charged functional groups of the zwitterionic molecule 5-aminolevulinic acid.

higher PpIX yield, but as they are more lipophilic, they are taken up via passive diffusion and may result in lower selectivity toward neoplastic cells [60,61]. While MAL and ALA have been approved for topical treatment of AK and basal cell carcinoma, only few studies exist that investigate the use of hexyl-ALA for epidermal neoplasms [62]. Another approach to circumvent the short half-life of ALA in solution is the immediate preparation before use, as in a two-chamber applicator device containing ALA and alcohol to produce a 20\% ALA solution [63].

Furthermore, ALA can be stabilized in combination with a specialized vehicle. A proprietary nanoscale lipidvesicle formulation patented by Biofrontera Bioscience $\mathrm{GmbH}$ (also termed nanoemulsion BF-200) has been reported to increase ALA stability [64]. A 10\% ALA-HCl gel formulation, containing 7.8\% free ALA, based on this vehicle is stable over 24 months [40] and has an open stability of 12 weeks, thereby increasing the ALA stability, which normally amounts only several days [65]. This effect can potentially be attributed to the interaction of the zwitterionic ALA-molecules with the polar phosphatidylcholine head groups of the lipids in the formulation (Figure 1). The advantage of such a physical stabilization is that unmodified ALA is provided to the cells so uptake and metabolism can start immediately. This faster conversion of ALA into PpIX has been shown in neoplastic keratinocytes [58]. While in healthy keratinocyte cells low level conversion of ALA and MAL to PpIX has been observed, the treatment of neoplastic SCC cells with ALA revealed higher PpIX fluorescence after 2.5 and $4.5 \mathrm{~h}$ compared with MAL-treated sample.

Interestingly, the nanoemulsion BF-200 seems to enhance penetration as well as epidermal PpIX formation $[53,64,66,67]$. In a porcine skin model in vitro, BF-200 ALA containing 7.8\% ALA was shown to be superior compared with a $20 \%$ MAL formulation, containing $16 \%$ free MAL, in terms of penetration depth and PpIX formation in the deeper epidermal layers [64]. In human skin explants, BF-200 ALA was compared with a standard $20 \%$ ALA cream formulation. The amount of ALA-induced PpIX was at least threefold higher at any measured time point [53]. Two additional studies could reproduce the increased PpIX formation attributed to BF-200 ALA compared with MAL in healthy volunteers' skin, focusing on either different age groups or pretreatments [66,67].

As referred to in the following paragraph, this improvement in penetration also results in a higher clinical efficacy of BF-200 ALA compared with an MAL preparation in mild-to-moderate AK on face and scalp [39,68].

The remaining question is: how does the nanoemulsion promote penetration and potentially also cellular uptake? The available evidence hints toward an interaction between the lipids and phospholipids of the nanoemulsion with lipid membranes, particularly in the stratum corneum. Nanovesicles will attach to the membrane and be dissolved 


\section{(A) Stratum corneum}

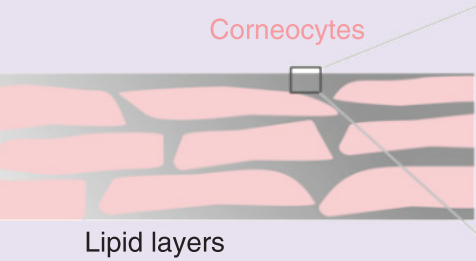

Lipid layers

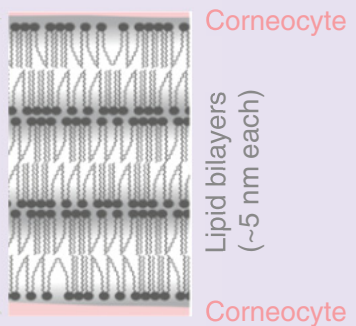

(B)

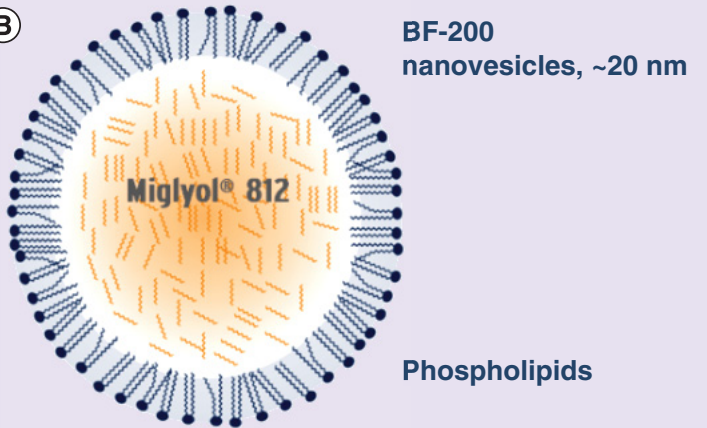

(C)

Merging process of nanoemulsion with stratum corneum
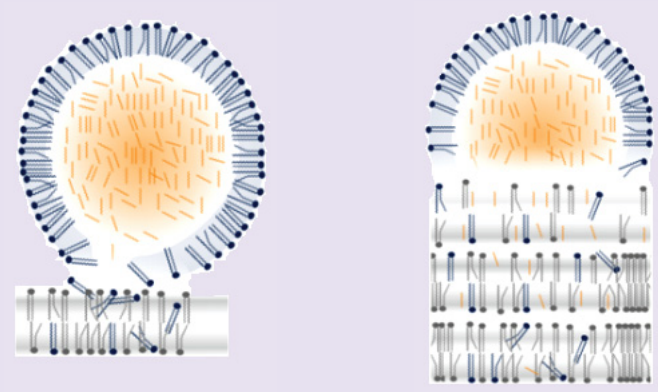

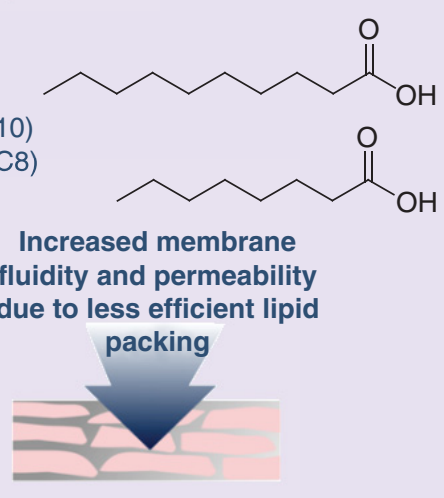

(D)
Miglyol ${ }^{\circledR} 812$ : Capric acid (C10) Caprylic acid (C8)

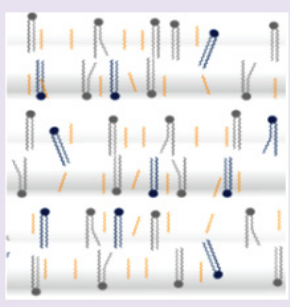

Increased membrane fluidity and permeability due to less efficient lipid

Figure 2. Proposed mode of action for the nanoemulsion BF-200 and the human stratum corneum. (A) The human stratum corneum is composed of corneocytes embedded in lipids. These are packed in lipid bilayers of $5 \mathrm{~nm}$ thickness. (B) The BF-200 nanovesicles have a mean diameter of approximately $20 \mathrm{~nm}$, are composed of a monolayer of phosphatidylcholine molecules and are filled with a mixture of C8 and C10 fatty acid molecules (Miglyol ${ }^{\circledR}$ 812). (C) Upon contact with the stratum corneum lipid layers, the nanovesicle is presumed to undergo a fusion process. Within this process the phospholipids integrate into the lipid bilayers and the vesicle content is able to intersperse with the membrane lipids. (D) The shorter chain fatty acids integrate into the stratum corneum bilayers and cause a less efficient packing of the membrane. This increases membrane fluidity, which finally allows for easier penetration of aminolevulinic acid.

in the membrane, temporarily changing membrane fluidity and the immediate lipid environment. In this state, membranes are more easily penetrated by hydrophilic molecules.

To visualize the fate of the BF-200 vesicles in the skin, the nanoemulsion was prepared with encapsulated 1,1'-Dioctadecyl-3,3,3',3'-tetramethylindocarbocyaninperchlorat (DiI; concentration $1.25 \mathrm{mM}$ ) and applied at $64 \mu \mathrm{l} / \mathrm{cm}^{2}$ to fresh, full thickness human skin obtained from reduction plastic surgery. DiI containing vesicles were then visualized by fluorescence microscopy. In this experimental setup, fluorescence appeared in the lipid layers of the stratum corneum. Elsewhere unpublished scientific observations from experiments carried out during BF-200 ALA development that were submitted as preclinical module to the EMA in the drug approval documentation. It is concluded that BF-200 nanovesicles rapidly fuse with biological membranes in its vicinity. The DiI-containing lipophilic components dissolve in the lipid lamellae of the stratum corneum or, in case of a disrupted stratum corneum, in the cellular membranes of the epidermis. The same conclusion has been suggested in an earlier study, in which the authors proposed that the resulting mixture of lipids in a membrane temporarily increases membrane fluidity, thus rendering the membrane easily penetrable [69,70].

An illustration of the proposed mode of action is depicted in Figure 2.

The lipids surrounding the corneocytes of the stratum corneum are composed as condensed membranous bilayered structures resembling bio membranes of vital cells (Figure 2A).

The shell of the $20 \mathrm{~nm}$ diameter nanovesicles in BF-200 ALA is entirely composed of phospholipids and the core contains a mixture of caprylic acid (C8) and capric acid (C10) (Figure 2B). Upon contact with the stratum corneum lipid layers, the nanovesicles supposedly undergo a merging process. This leads to the incorporation of both the phospholipids as well as the shorter chain fatty acids into the membranes (Figure 2C). Interspersion of the shorter chain lipids into the stratum corneum bilayers may increase their fluidity and hence induce a higher 
Table 1. Comparative efficacy data (Full Analysis Set (FAS)/ Intent-To-Treat (ITT) population) from the Phase III trials with BF-200 ALA.

\begin{tabular}{|c|c|c|c|c|c|c|c|}
\hline & \multicolumn{2}{|c|}{ Szeimies et al. (2010) } & \multicolumn{3}{|c|}{ Dirschka et al. (2012) } & \multicolumn{2}{|c|}{ Reinhold et al. (2016) } \\
\hline & BF-200 ALA & Placebo & BF-200 ALA & MAL & Placebo & BF-200 ALA & Placebo \\
\hline \multicolumn{8}{|c|}{ Patient complete clearance } \\
\hline After first PDT & $47.5 \%^{\dagger}$ & $10.0 \%$ & $48.4 \%^{\dagger, \ddagger}$ & $37.0 \%$ & $3.9 \%$ & $61.8 \%^{\dagger}$ & $9.4 \%$ \\
\hline After last PDT ${ }^{\S}$ & $64.0 \%{ }^{\dagger}$ & $11.0 \%$ & $78.2 \%$ & $64.2 \%$ & $17.1 \%$ & $90.9 \%{ }^{\dagger}$ & $21.9 \%$ \\
\hline Broad spectrum & $53.1 \%$ & $12.0 \%$ & $71.5 \%^{\dagger}$ & $61.3 \%$ & $12.8 \%$ & NA & NA \\
\hline Narrow spectrum & $87.1 \%$ & $13.3 \%$ & $84.8 \%^{\dagger, \ddagger}$ & $67.5 \%$ & $21.6 \%$ & $90.9 \%^{\dagger}$ & $21.9 \%$ \\
\hline \multicolumn{8}{|c|}{ Lesion complete clearance } \\
\hline After first PDT & $69.0 \%$ & $19.1 \%$ & $73.8 \%$ & $66.5 \%$ & $24.7 \%$ & $84.2 \%$ 『 & $22.0 \%$ \\
\hline After last PDT & $81.1 \%$ & $20.9 \%$ & $90.4 \%$ & $83.2 \%$ & $37.1 \%$ & $94.3 \%^{\dagger}$ & $32.9 \%$ \\
\hline Broad spectrum & $70.5 \%$ & $24.6 \%$ & $86.3 \%^{\dagger, \ddagger}$ & $76.3 \%$ & $42.8 \%$ & NA & NA \\
\hline Narrow spectrum & $96.3 \%$ & $15.1 \%$ & $93.6 \%^{t, t}$ & $89.3 \%$ & $32.5 \%$ & $94.3 \%^{\dagger}$ & $32.9 \%$ \\
\hline \multicolumn{8}{|c|}{$\begin{array}{l}{ }^{\dagger} \text { BF-200 ALA significantly superior to placebo (at least } p<0.01 \text { ). } \\
\text { †BF-200 ALA significantly superior to MAL (at least } p<0.05 \text { ). } \\
\text { §Primary efficacy variable. } \\
\text { `Not tested for significance. } \\
\text { ALA: Aminolevulinic acid; MAL: Methyl-aminolevulinic acid; NA: Not available. } \\
\text { Data taken from }[68,78,80] .\end{array}$} \\
\hline
\end{tabular}

permeability due to a decreased packing density of the stratum corneum lipids [71]. This state is very likely to allow for a higher amount of ALA molecules to overcome the stratum corneum and reach the skin's vital layers, where they can enter cells and be distributed by diffusion (Figure 2D).

With respect to safety, it has to be pointed out that BF-200 does not contain solid nanoparticles. Solid nanoparticles (e.g., nanocrystals or metal nanoparticles) as used in some transparent sunscreens, water repellents, surface-coating sprays or as produced by diesel engines have been reported to represent potential health hazards, both medically and environmentally [72], and are not components of BF-200.

The publication of Hirano introduces a definition for nanoparticles as 'particulate substances of nanoscale dimensions,' and the examples provided are nanoparticles of, for example, carbon, metal oxides or polymers.

Phosphatidylcholine is the major component of the emulsifier monolayer of BF-200. Phosphatidylcholines are major components of biological membranes. All eukaryotic cell membranes contain phosphatidylcholine. Phosphatidylcholine and the other constituents of BF-200 are metabolized by the regular lipid metabolism of cells.

In summary, the oil-in-water nanoemulsion BF-200 is a safe and effective way to stabilize ALA and enhance its penetration into the epidermis.

\section{Light sources for PDT of the skin}

Based on the PpIX absorption spectrum, comprised of one Soret band and four Q-bands, different light sources with different characteristics can be used to excite PpIX for PDT [73]. One approach is the use of broad spectrum light sources to cover a continuous spectrum above $590 \mathrm{~nm}$ and thereby excite PpIX, but with a low total light dose. Another option is the use of narrow spectrum light sources. Here, two excitation peaks are most relevant: the excitation peak in the blue sections $(405 \mathrm{~nm})$ and in the red section $(630 \mathrm{~nm})$. Albeit blue light shows the highest excitation peak, its penetration into the skin is limited to $<1 \mathrm{~mm}$. In contrast, red light shows a lower excitation peak, but therefore penetrates several millimeter into the skin, reaching the bottom of thicker lesions [44,73-75]. In the USA, PDT is performed with narrow spectrum light sources to excite the photosensitizer at the specific wavelength, either in the blue section or the red section.

Compared with broad spectrum light sources, light intensity of light-emitting diode (LED) light sources (Figure 3) is about 30-fold higher which may be the cause for higher potency in the induction of cell death in vitro and in Phase III trials when using LED lamps [68,76-79].

The choice of the light source can have a high impact on the efficacy of photodynamic therapy. This influence was observed in two Phase III studies that evaluated the safety and efficacy of PDT for AK with BF-200 ALA (Table 1). The results of both studies revealed higher efficacy rates for patient and lesion complete clearance treated with red narrow spectrum LED lamps compared with broad spectrum lamps [68,78]. A similar effect regarding better treatment efficacy has been observed for the BF-200 ALA comparator MAL when using a narrow spectrum 
(A)

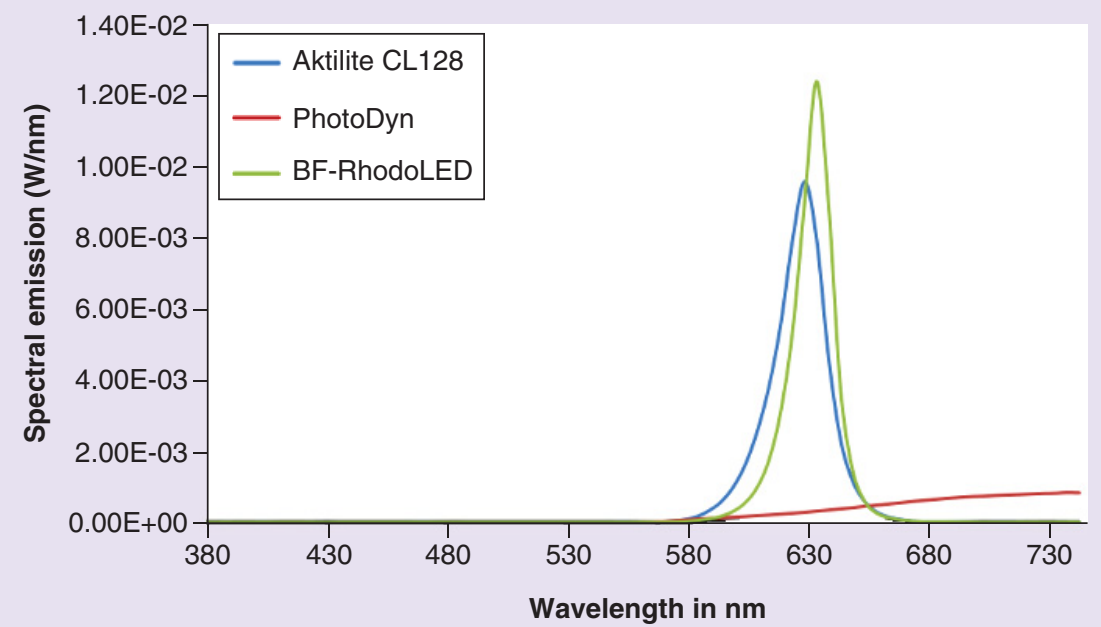

(B)

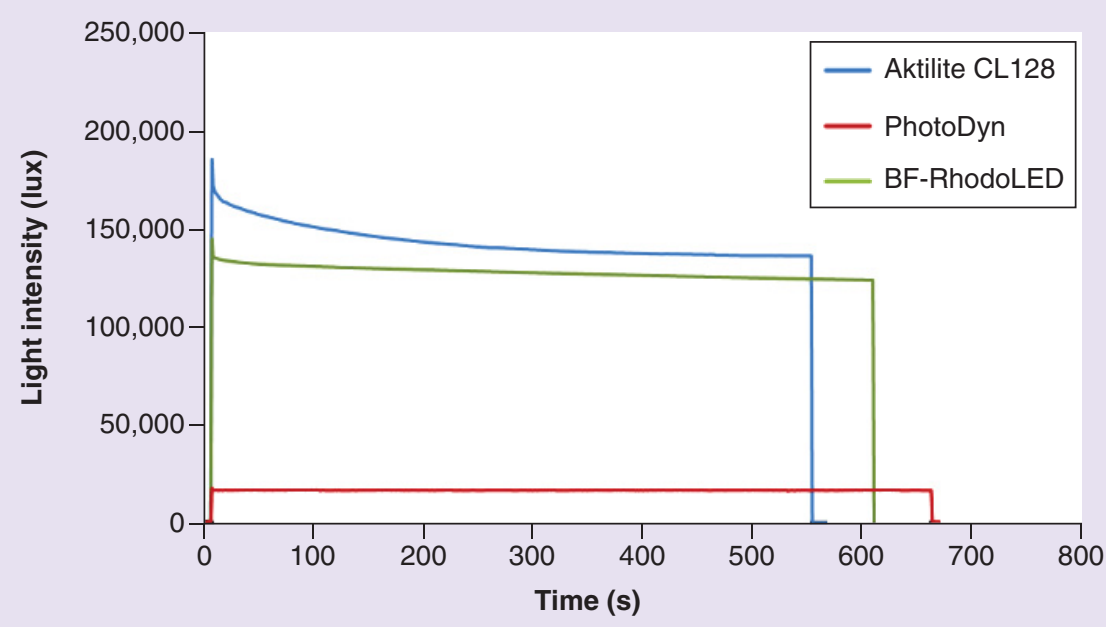

Figure 3. Measurement of physical parameters of three commercially available photodynamic therapy lamps, two light-emitting diode (BF-RhodoLED ${ }^{\circledR}$ and Aktilite ${ }^{\circledR}$ ) and one broad-spectrum system (PhotoDyn ${ }^{\circledR}$ 750). (A) Spectral emission of the three analyzed lamps measured in $\mathrm{W} / \mathrm{nm}$. Light intensities were assessed and plotted against wavelength in the range of visible light from 380 to $740 \mathrm{~nm}$. (B) Light intensity emitted from the three analyzed lamps over the time course of an illumination leading to an emitted light dose of $37 \mathrm{~J} / \mathrm{cm}^{2}$ (light-emitting diode lamps) or $170 \mathrm{~J} / \mathrm{cm}^{2}$ (broad spectrum lamp). Intensities were measured in lux and plotted against time in seconds. Reproduced with permission from [79].

light [68]. By comparison, lesion complete clearance in the BF-200 ALA group was significantly superior to MAL, in the narrow spectrum and broad spectrum group, respectively [68].

In summary, these studies revealed that red narrow spectrum LED lamps achieve higher efficacies. These efficacies were associated with elevated pain and local skin reactions, but showing a higher activation of the photosensitizer and a deeper penetration with the red narrow spectrum light.

\section{Clinical data summary of Phase III trials for the treatment of actinic keratosis with BF-200 ALA} In the EU, BF-200 ALA holds approval for the treatment of actinic keratosis of mild-to-moderate severity on the face and scalp (Olsen grade 1 to 2) and of field cancerization in adults. Additionally, BF-200 ALA is approved in the EU for the treatment of superficial and/or nodular basal cell carcinoma unsuitable for surgical treatment due to possible treatment-related morbidity and/or poor cosmetic outcome in adults [40]. In the USA, BF-200 ALA is 
indicated for the lesion-directed and field-directed treatment of actinic keratoses of mild-to-moderate severity on the face and scalp in combination with photodynamic therapy using BF-RhodoLED ${ }^{\circledR}$ lamp [41].

\section{Method of administration of BF-200 ALA for actinic keratosis}

As BF-200 ALA is an oil-in-water nanoemulsion, degreasing of the skin is beneficial for its absorption. Therefore short-chain alcoholic substances or mixtures (ethanol, 2-propanol) that do not contain additional lipid-replenishing agents can be used. Next, scales and crusts should be removed and lesion surfaces roughened, for example, by curettage. Afterward, the BF-200 ALA nanoemulsion should be applied with a thickness of about $1 \mathrm{~mm}$ to AK lesions or cancerized fields $\left(20 \mathrm{~cm}^{2}\right)$ with a surrounding $5 \mathrm{~mm}$ margin of healthy tissue. The gel is then allowed to dry for a few (at maximum $10 \mathrm{~min}$ ), before a light-tight occlusive dressing is applied. After $3 \mathrm{~h}$ of incubation, the occlusion and residual gels are removed and illumination with spectrum light source according to approval situation can be performed [40,41]. The shelf-life of BF-200 ALA after first opening and storage in the refrigerator $\left(2-8^{\circ} \mathrm{C}\right)$ is 12 weeks.

\section{Clinical efficacy}

Efficacy and safety of BF-200 ALA for actinic keratosis were studied in three pivotal randomized controlled Phase III trials conducted in Germany, Austria and Switzerland [68,78,80]. All enrolled patients suffered from four to eight mild and moderate actinic keratosis on the face and scalp and were treated with up to two PDTs 12 weeks apart. A second PDT was only administered when the patient was not completely cleared after the first session. The primary end point was always patient complete clearance after 12 weeks following the last PDT. The types of red light sources used during the studies are specified below.

In a first study by Szeimies et al. in 2010, BF-200 ALA was compared with placebo in 122 patients [78]. The red light source provided either a narrow spectrum around $630 \mathrm{~nm}$ at a light dose of $37 \mathrm{~J} / \mathrm{cm}^{2}$ (Aktilite ${ }^{\circledR}$ CL 128) or a broader and continuous spectrum in the range between 570 and $670 \mathrm{~nm}$ at a light dose of $170 \mathrm{~J} / \mathrm{cm}^{2}$ (Photodyn ${ }^{\circledR}$ 750). The primary end point was complete patient clearance, defined as all lesions considered to be cleared by clinical and histological assessment. For histological assessment, biopsies of a representative lesion were taken before and after PDT. Photodynamic therapy with BF-200 ALA (64\%) was significantly more effective than with placebo $(11 \%, \mathrm{p}<0.0001)$. Total lesion clearance was also higher for BF-200 ALA $(81.1 \%)$ compared with placebo $(20.9 \%)$. Clearance was dependent on the illumination source in favor of the narrow spectrum light source. Patient complete clearance after the last PDT was $87.1 \%$ using the narrow-spectrum lamp compared with $53.1 \%$ using the broad-spectrum lamp. Corresponding complete lesion clearance rates were 96.3 and $70.5 \%$. Lesion clearance rates using placebo (narrow: 15.1\%; broad: $24.6 \%$ ) were clearly lower compared with verum with both illumination systems.

Clinical efficacy was maintained during the follow-up periods of 6 and 12 months [39]. The probability of a subject to remain cleared 12 months after the last treatment with BF-200 ALA with narrow spectrum lamps was 67.5 or $46.8 \%$ when using all lamp types, respectively. The probability to require only one treatment with BF-200 ALA and remain completely cleared 12 months later was $34.5 \%$ on average with all lamps.

The second study was a randomized, observer blind trial including 571 AK patients [68]. BF-200 ALA was tested for noninferiority and superiority in a hierarchical scheme according to EMA guidelines to a commercially available 16\% methyl-aminolevulinate (MAL) cream and for superiority over placebo. The red light source was either a narrow light spectrum lamp (Aktilite CL 128 or Omnilux ${ }^{\circledR}$ PDT) or a lamp with a broader and continuous light spectrum (Waldmann ${ }^{\circledR}$ PDT 1200 L, or Hydrosun ${ }^{\circledR}$ Photodyn 505 or 750 ). The primary end point was complete patient clearance 12 weeks after the last photodynamic therapy, defined as all lesions of a patient to be cleared by clinical assessment. Here, BF-200 ALA (78.2\%) was significantly more effective than MAL (64.2\%) and placebo (17.1\%). The superiority over MAL could also be demonstrated in the subgroup of patients treated with LED lamps only (84.8 vs $67.5 \% ; \mathrm{p}=0.0013)$.

Also the total lesion clearance rates were higher for BF-200 ALA (90.4\%) compared with MAL (83.2\%) and placebo (37.1\%). Exploratory statistics could also reveal a significant superiority of BF-200 ALA toward MAL for lesion complete clearance in both the subgroups with either broad-spectrum or LED lamps. For LED lamps, lesion clearance rates were $93.6 \%$ for BF-200 ALA and 89.3\% for MAL ( $\mathrm{p}=0.0014$ ). For broad-spectrum lamps, the results were at $86.3 \%$ for BF-200 ALA and at 76.3\% with MAL ( $<<0.0001)$. 


\begin{tabular}{|c|c|c|c|c|}
\hline & \multicolumn{2}{|c|}{ Placebo } & \multicolumn{2}{|c|}{ BF-200 ALA } \\
\hline & $\mathrm{n} / \mathrm{N}(\%)$ & $\mathrm{Cl}$ & $\mathrm{n} / \mathrm{N}(\%)$ & $\mathrm{Cl}$ \\
\hline Skin surface (roughness/dryness/scaliness) & $8 / 25(32.0)$ & $14.9 ; 53.5$ & $32 / 46(69.6)$ & $54.2 ; 82.3$ \\
\hline Hyperpigmentation (independent of texture change or hypopigmentation) & $5 / 20(25.0)$ & $8.7 ; 49.1$ & $14 / 32(43.8)$ & $26.4 ; 62.3$ \\
\hline Hypopigmentation (independent of texture change or hyperpigmentation) & $2 / 13(15.4)$ & $1.9 ; 45.4$ & $11 / 25(44.0)$ & $24.4 ; 65.1$ \\
\hline Degree of scarring (independent of pigmentary changes) & $1 / 8(12.5)$ & $0.3 ; 52.7$ & $5 / 14(35.7)$ & $12.8 ; 64.9$ \\
\hline Atrophy & $0 / 9(0.0)$ & $0.0 ; 33.6$ & $8 / 17(47.1)$ & $23.0 ; 72.2$ \\
\hline
\end{tabular}

In both studies, also tolerability was dependent on the illumination source, with narrow-band lamps inducing higher rates of pain and burning during the illumination phase than broad spectrum lights [68,78]. However, there was no difference between BF-200 ALA and MAL in terms of pain or treatment emerged adverse events [68].

Moreover, in this study, efficacy was clinically assessed during follow-up visits at 6 and 12 months after the last treatment [39]. Recurrence rates after 12 months were $41.6 \%$ for BF-200 and 44.8\% for MAL, depending on the light spectrum and in favor of narrow spectrum lamps. The probability to remain completely cleared 12 months after the last treatment was 53.1 or $47.2 \%$ for treatment with BF-200 ALA and 40.8 or $36.3 \%$ for MAL treatment with narrow spectrum lamps or all lamp types, respectively. The probability of patients in the BF-200 ALA group to require only a single PDT session and to remain cleared 12 months after was 32.3 and $22.4 \%$ in the MAL group (average over all lamp types).

The third study differed from the two previous ones in respect to the application area of BF-200 ALA, choosing a field-directed approach [80]. Instead of applying BF-200 ALA only to lesions and a surrounding $5 \mathrm{~mm}$ margin of healthy tissue, the drug was applied to $20 \mathrm{~cm}^{2}$ areas (containing 4-8 visible AK lesions), with the intention to target field cancerization. Field cancerization is described as an area of skin in which multiple, visible AK lesions are present, with a high probability of additional underlying and surrounding actinic damage (a concept also known as field change). A total of 87 patients were enrolled, to be treated with BF-200 ALA and placebo. The red light source provided a narrow spectrum around $635 \mathrm{~nm}$ at a light dose of $37 \mathrm{~J} / \mathrm{cm}^{2}$. BF-200 ALA has been proven superior to placebo for the primary end point patient complete clearance ( 90.9 vs $21.9 \%$ for BF-200 ALA and placebo, respectively; $\mathrm{p}<0.0001$ ) and lesion complete clearance rates ( 94.3 vs $32.9 \%$, respectively; $\mathrm{p}<0.0001$ ), as controlled 12 weeks after the last PDT. Clearance of lesions was assessed by visual inspection and palpation. For histological confirmation, biopsies of a representative lesion were taken before and after PDT. Subgroup analyses revealed that with BF-200 ALA, $96.9 \%$ of patients with AK on the face or forehead and $81.8 \%$ of patients with AK on the scalp were cleared of all lesions. Lesions of mild severity were cleared by 99.1 versus $49.2 \%$, those of moderate severity by 91.7 versus $24.1 \%$ when treated with BF-200 ALA and placebo, respectively. With a single PDT a complete patient clearance of 61.8 versus $9.4 \%$, and complete lesion clearance of 84.2 versus $22.0 \%$ was achieved for BF-200 ALA and placebo treatment, respectively. Efficacy was maintained over the follow-up period, with $63.3 \%$ of the patients still remaining completely cleared after 12 months.

All efficacy data at the primary end point are summarized for all three studies in Table 1.

\section{Cosmetic outcome}

Photodynamic therapy has been frequently reported to have a beneficial cosmetic effect on the treated skin [81]. This effect can be attributed to the removal of the AK lesions and irregular pigmentation, but also to additional dermal effects (see Table 2). The inflammatory response associated with PDT is often accompanied by the dermal formation of collagen which leads to an improved skin appearance in the treated area. This has been reported by several authors and becomes especially evident when performing field-directed PDT [82-85]. In the recent pivotal study evaluating BF-200 ALA in field-directed PDT, the cosmetic outcome was diligently studied and reported on a Phase III level [80]. All measured parameters improved substantially after PDT with BF-200 ALA (see Table 2). The number of patients without skin surface impairment increased from 15 to $63 \%$ after BF-200 ALA treatment, and the frequency of patients without irregular pigmentation in the treatment area, including hyper- as well as 
hypopigmentation, increased from 52 to $70 \%$. Thus, rather than causing irregular pigmentation, PDT improves it over 12 months after treatment $[40,80]$.

Especially skin surface and pigmentation parameters are greatly improved and unpublished follow-up data indicate that this improvement is not only maintained but even progressing during the follow-up period. This signifies the sustainability of PDT not only in the long-term management of AK but also in terms of cosmetic outcome [80].

\section{Clinical safety}

In the Phase III clinical trials with BF-200 ALA, local skin reactions at the application site were observed in up to $96 \%$ of the patients treated for actinic keratosis $[68,78,80]$. As the therapeutic principle of PDT is based on the photodynamic cytotoxicity caused by protoporphyrin IX, this was to be expected. Most side effects had their onset during illumination or immediately afterward, were of mild-to-moderate intensity and short-lasting. In some cases, side effects lasted up to 1 to 2 weeks or longer. Most common were application site irritation, erythema, pain and edema. The increased efficacy due to narrow-spectrum lamps was also associated with a higher frequency of side effects $[68,78,80]$.

Pain during the illumination has received much attention in research and pain mechanisms were discussed in some detail elsewhere $[57,86,87]$.

It is noteworthy that an equal sensation of pain is observed regardless if BF-200 ALA or MAL is administered. Pain is generally more severe, when narrow-spectrum devices are used [68]. Additionally, when indirectly comparing pain scores from lesion and field directed treatments using BF-200 ALA and an LED light source, there is no sign of increased pain during field treatment $[68,78,80]$. Nonetheless, an appropriate form of pain management has to be considered, whenever PDT is directed to larger fields, as treatment area size is a well-known predictor of PDT pain [88]. Since pain intensity is associated with light intensity, LED lamps have been developed that allow reduction of light intensity, but keep the fluence constant $[89,90]$. Using this feature, pain can be greatly reduced.

However, strategies to circumvent, reduce or cope with PDT-induced pain are of importance for the dermatological community [87-88,91]. During recent years, modified PDT protocols using natural or simulated daylight have been developed which can be implemented to manage pain in clinical routine.

\section{PDT with natural \& simulated daylight}

Daylight-PDT takes advantage of the natural visual spectrum of light which contains the necessary wavelengths to excite PpIX. In addition to the change in light source, the protocol is altered regarding incubation time [92-95]. Instead of a long incubation with a short illumination (c-PDT), daylight-PDT is performed with a short incubation and long illumination. More precisely, while during c-PDT a high amount of PpIX accumulates and is excited within short time, DL-PDT relies on the constant production and excitation of PpIX molecules within $2 \mathrm{~h}$. Therefore a microphototoxic effect is postulated for DL-PDT, in contrast to a massive phototoxic effect induced by c-PDT $[96,97]$.

BF-200 ALA has been studied in daylight PDT: In a nonsponsored randomized double-blinded split face study BF-200 ALA and MAL were compared in daylight photodynamic therapy [98]. Patients with AK grade I lesions were treated once, while AK grade II lesions were treated twice, 1 week apart. The procedure included the use of a sun protection prior to treatment, curettage, application of photosensitizer precursor $(0.25 \mathrm{~mm}$ layer $)$, an incubation (30 $\mathrm{min}), 2 \mathrm{~h}$ illumination with natural daylight and wiping off any residual photosensitizer after those 2 h. Complete clinical lesion clearance rates were $84.5 \%$ for BF-200 ALA and $74.2 \%$ for MAL after 3 months with no difference in pain or adverse reactions [98]. Histological clearance was $61.5 \%$ with BF-200 ALA compared with only 38.5\% with MAL. Based on the follow-up data assessed 12 months after the last treatment, the complete lesion response, including baseline and new lesions, revealed efficacies of $83.3 \%$ for BF-200 ALA and 59.1\% for MAL [99].

Since assuring constant conditions for daylight-PDT is difficult [100], simulated daylight-PDT (SDL-PDT) has been developed. It can be performed in the doctor's office under standardized, constant conditions with the possibility to monitor the patient at all times. One example is the Indoorlux ${ }^{\circledR}$ system (Swiss Red AG, Switzerland), which is intended to be used with a protocol compared with daylight-PDT and uses a light spectrum ranging from 570 to $630 \mathrm{~nm}$. This system has an illuminance of 15,000-25,000 lux depending on the distance of the light source, which is installed at the ceiling of the treatment room. In a retrospective study, the efficacy and safety of PDT with the Indoorlux system using the BF-200 ALA nanoemulsion was evaluated [101]. A total of 32 patients 
with mild-to-moderate AKs on the face and/or scalp were include in this trial and were treated once, followed by a second treatment 1 week later. After applying the gel and an occlusive dressing for $30 \mathrm{~min}$, patients were seated in the illumination room and pain was assessed after 30,60 and $90 \mathrm{~min}$. Twelve weeks after the second treatment complete patient clearance for SDL-PDT with BF-200 ALA was 75\%. In patients with AK grade I lesions only, efficacy was $82.4 \%$, while patients with at least one AK grade II lesion showed complete clearance rates of $66.7 \%$. The total lesion clearance rate for SDL-PDT with BF-200 ALA was 92.8\%. This method was well tolerated by the patients with no to mild pain.

Taking everything into consideration, DL- and SDL-PDT can be especially beneficial when treating extended fields of visible and subclinical lesions, due to negligible pain during therapy combined with very high efficacies compared with other treatment options. The reduced pain experienced during DL-/SDL-PDT may lead to a better therapy acceptance among patients. For thicker AK lesions, possibly remaining after DL-PDT, conventional PDT with narrow spectrum light sources is especially efficient. Thus, the combination of both approaches in an alternating and synergistic fashion seems sensible from a medical and an economical point of view, maximizing the benefit of patients.

\section{Conclusion}

Based on the facts presented here it is of high interest to develop a protocol that combines all benefits of each PDT approach, for example, high efficacy and high patient acceptance. One option could be a field-directed treatment

\section{Executive summary}

- Actinic keratosis is prone to affect entire skin regions (field cancerization) and represents the first step in a disease continuum toward invasive squamous cell carcinoma.

- Recent studies show that even lower grade actinic keratosis (AK) possesses the capability to progress toward invasion. Therefore, an early and sustainable treatment is recommended.

Photodynamic therapy for AK

- Photodynamic therapy has been widely studied in the field of AK.

- This selective approach is based on a photosensitizer that is excited by light of a specific wavelength leading to the formation of reactive oxygen species and the initiation of cell death.

- Usually a prodrug is applied topically and therefore epidermal penetration, next to selectivity and stability, plays an important role.

Enhancing photodynamic therapy with nanoemulsion technology

- The nanoscale-lipid-vesicle formulation BF-200 can be combined with the photosensitizer prodrug aminolevulinic acid (ALA) to enhance both prodrug stability and penetration as shown in preclinical studies.

- The lipid composition in BF-200 may alter membrane fluidity to facilitate epidermal absorption of small hydrophilic molecules.

Light sources for dermatological photodynamic therapy

- While different light sources can be used for conventional photodynamic therapy (PDT), in clinical trials with BF-200 ALA, it is has been demonstrated that narrow spectrum light sources result in higher clearance rates compared with broad spectrum light sources.

Clinical data summary of Phase III trials with BF-200 ALA

- Phase III clinical trials with BF-200 ALA could demonstrate its efficacy in field and lesion-directed photodynamic therapy using broad and red narrow band light. BF-200 ALA has been proven superior compared with an MAL formulation and placebo in a three-armed comparator trial, and to placebo into additional trials.

- The drug showed a favorable risk-benefit-ratio and clearance rates as well as the cosmetic outcome were sustained during follow-up evaluations.

PDT with natural \& simulated daylight

- With respect to pain, DL- and SDL-PDT are well-tolerable options in the treatment of AK, but have limitations compared with light-emitting diode driven PDT when treating thicker lesions.

Conclusion

- Field-directed AK treatment can be effectively executed with BF-200 ALA PDT and should be used for sustainable, long-term disease management in order to prevent disease progression.

- PDT has a well-established skin rejuvenation effect which was studied in Phase III for BF-200 ALA.

- Different light-sources allow for optimization and adaption of PDT protocols, tailored to the patients' individual needs.

- The medical along with the cosmetic benefits strongly argue in favor of treatment protocols where always the entire tube of BF-200 ALA is applied to an extended treatment field per PDT session for AK. 
with DL-PDT/SDL-PDT for lower-grade and clinically invisible AKs, followed by a treatment with c-PDT for residual lesions. Finally, it is most important to prevent further progression into SCCs, therefore high complete clearance rates for single lesions and cancerized fields are of high relevance when deciding for a treatment. These high efficacies in AK treatment revealed by PDT can lead to a reduction in the need for re-treatment and thereby an increase in patient satisfaction.

\section{Acknowledgements}

The author acknowledges the editorial support and help of N Pospiech and B Novak during the preparation of this manuscript.

Financial \& competing interests disclosure

The author has received speaker's fees and travel grants from and acted as advisor and consultant for the company which commercializes BF-200 ALA. The author has no other relevant affiliations or financial involvement with any organization or entity with a financial interest in or financial conflict with the subject matter or materials discussed in the manuscript apart from those disclosed.

\section{References}

Papers of special note have been highlighted as: $\bullet$ of interest; $\bullet \bullet$ of considerable interest

1. Jonason AS, Kunala S, Price GJ et al. Frequent clones of p53-mutated keratinocytes in normal human skin. Proc. Natl Acad. Sci. USA 93(24), 14025-14029 (1996).

2. Rigel DS, Stein Gold LF. The importance of early diagnosis and treatment of actinic keratosis. J. Am. Acad. Dermatol. 68(1 Suppl. 1), S20-S27 (2013).

3. Glogau RG. The risk of progression to invasive disease. J. Am. Acad. Dermatol. 42(1 Pt 2), 23-24 (2000).

4. Salasche SJ. Epidemiology of actinic keratoses and squamous cell carcinoma. J. Am. Acad. Dermatol. 42(1 Pt 2), 4-7 (2000).

5. Frost CA, Green AC. Epidemiology of solar keratoses. Br. J. Dermatol. 131(4), 455-464 (1994).

6. Memon AA, Tomenson JA, Bothwell J, Friedmann PS. Prevalence of solar damage and actinic keratosis in a Merseyside population. Br. J. Dermatol. 142(6), 1154-1159 (2000).

7. Siegel JA, Korgavkar K, Weinstock MA. Current perspective on actinic keratosis: a review. Br. J. Dermatol. 177(2), 350-358 (2017).

8. Costa C, Scalvenzi M, Ayala F, Fabbrocini G, Monfrecola G. How to treat actinic keratosis? An update. J. Dermatol. Case Rep. 9(2), 29-35 (2015).

9. Ouyang YH. Skin cancer of the head and neck. Semin. Plast. Surg. 24(2), 117-126 (2010).

10. Braathen LR, Szeimies RM, Basset-Seguin N et al. Guidelines on the use of photodynamic therapy for nonmelanoma skin cancer: an international consensus. J. Am. Acad. Dermatol. 56(1), 125-143 (2007).

11. Werner RN, Sammain A, Erdmann R, Hartmann V, Stockfleth E, Nast A. The natural history of actinic keratosis: a systematic review. Br. J. Dermatol. 169(3), 502-518 (2013).

12. Fernandez-Figueras MT, Carrato C, Saenz X et al. Actinic keratosis with atypical basal cells (AK I) is the most common lesion associated with invasive squamous cell carcinoma of the skin. J. Eur. Acad. Dermatol. Venereol. 29(5), 991-997 (2015).

13. Fernandez Figueras MT. From actinic keratosis to squamous cell carcinoma: pathophysiology revisited. J. Eur. Acad. Dermatol. Venereol. 31(Suppl. 2), 5-7 (2017).

14. Chetty P, Choi F, Mitchell T. Primary care review of actinic keratosis and its therapeutic options: a global perspective. Dermatol. Ther. 5(1), 19-35 (2015).

15. Uhlenhake EE. Optimal treatment of actinic keratoses. Clin. Interv. Aging. 8, 29-35 (2013).

16. Werner RN, Stockfleth E, Connolly SM et al. Evidence- and consensus-based (S3) Guidelines for the Treatment of Actinic Keratosis International League of Dermatological Societies in cooperation with the European Dermatology Forum - short version. J. Eur. Acad. Dermatol. Venereol. 29(11), 2069-2079 (2015).

17. Olsen EA, Abernethy ML, Kulp-Shorten C et al. A double-blind, vehicle-controlled study evaluating masoprocol cream in the treatment of actinic keratoses on the head and neck. J. Am. Acad. Dermatol. 24(5 Pt 1), 738-743 (1991).

18. Rowert-Huber J, Patel MJ, Forschner T et al. Actinic keratosis is an early in situ squamous cell carcinoma: a proposal for reclassification. Br. J. Dermatol. 156(Suppl. 3), 8-12 (2007).

19. Schmitz L, Kahl P, Majores M, Bierhoff E, Stockfleth E, Dirschka T. Actinic keratosis: correlation between clinical and histological classification systems. J. Eur. Acad. Dermatol. Venereol. 30(8), 1303-1307 (2016).

20. Dirschka T, Pellacani G, Micali G et al. A proposed scoring system for assessing the severity of actinic keratosis on the head: actinic keratosis area and severity index (AKASI). J. Eur. Acad. Dermatol. Venereol. 31(8), 1295-1302 (2017).

21. Brash DE, Ziegler A, Jonason AS, Simon JA, Kunala S, Leffell DJ. Sunlight and sunburn in human skin cancer: p53, apoptosis, and tumor promotion. J. Investig. Dermatol. Symp. Proc. 1(2), 136-142 (1996). 
22. Ratushny V, Gober MD, Hick R, Ridky TW, Seykora JT. From keratinocyte to cancer: the pathogenesis and modeling of cutaneous squamous cell carcinoma. J. Clin. Invest. 122(2), 464-472 (2012).

23. Babilas P, Landthaler M, Szeimies RM. [Actinic keratoses]. Hautarzt 54(6), 551-560 (2003).

24. Slaughter DP, Southwick HW, Smejkal W. Field cancerization in oral stratified squamous epithelium; clinical implications of multicentric origin. Cancer 6(5), 963-968 (1953).

25. Braakhuis BJ, Tabor MP, Kummer JA, Leemans CR, Brakenhoff RH. A genetic explanation of Slaughter's concept of field cancerization: evidence and clinical implications. Cancer Res. 63(8), 1727-1730 (2003).

26. Szeimies RM, Torezan L, Niwa A et al. Clinical, histopathological and immunohistochemical assessment of human skin field cancerization before and after photodynamic therapy. Br. J. Dermatol. 167(1), 150-159 (2012).

27. Philipp-Dormston WG. Field cancerization: from molecular basis to selective field-directed management of actinic keratosis. Curr. Probl. Dermatol. 46, 115-121 (2015).

28. Cohen JL. Actinic keratosis treatment as a key component of preventive strategies for nonmelanoma skin cancer. J. Clin. Aesthet. Dermatol. 3(6), 39-44 (2010).

29. Criscione VD, Weinstock MA, Naylor MF, Luque C, Eide MJ, Bingham SF. Actinic keratoses: natural history and risk of malignant transformation in the Veterans Affairs Topical Tretinoin Chemoprevention Trial. Cancer 115(11), 2523-2530 (2009).

30. Neidecker MV, Davis-Ajami ML, Balkrishnan R, Feldman SR. Pharmacoeconomic considerations in treating actinic keratosis. PharmacoEconomics 27(6), 451-464 (2009).

31. Ibrahim SF, Brown MD. Actinic keratoses: a comprehensive update. J. Clin. Aesthet. Dermatol. 2(7), $43-48$ (2009).

32. Ceilley RI, Jorizzo JL. Current issues in the management of actinic keratosis. J. Am. Acad. Dermatol. 68(1 Suppl. 1), S28-S38 (2013).

33. Stockfleth E, Ferrandiz C, Grob JJ, Leigh I, Pehamberger H, Kerl H. Development of a treatment algorithm for actinic keratoses: a European Consensus. Eur. J. Dermatol. 18(6), 651-659 (2008).

34. Martin GM. Impact of interval and combination therapies on the management of actinic keratosis: review and clinical considerations. $J$. Dermatolog. Treat. 22(5), 288-297 (2010).

35. Wolf JE Jr, Rigel DS. Understanding efficacy end-points in studies of field-directed therapy for actinic keratosis. Int. J. Dermatol. 52(9), 1063-1070 (2013).

36. De Berker D, Mcgregor JM, Mohd Mustapa MF, Exton LS, Hughes BR. British Association of Dermatologists' guidelines for the care of patients with actinic keratosis 2017. Br. J. Dermatol. 176(1), 20-43 (2017).

37. Vegter S, Tolley K. A network meta-analysis of the relative efficacy of treatments for actinic keratosis of the face or scalp in Europe. PLoS ONE 9(6), e96829 (2014).

-• Network meta-analysis comparing the efficacies of all treatments approved for actinic keratosis (AK) in the EU.

38. Gupta AK, Paquet M, Villanueva E, Brintnell W. Interventions for actinic keratoses. Cochrane Database Syst. Rev. 12, CD004415 (2012).

39. Dirschka T, Radny P, Dominicus R et al. Long-term (6 and 12 months) follow-up of two prospective, randomized, controlled Phase III trials of photodynamic therapy with BF-200 ALA and methyl aminolaevulinate for the treatment of actinic keratosis. $\mathrm{Br}$. $\mathrm{J}$. Dermatol. 168(4), 825-836 (2013).

- One year follow-up data on two Phase III clinical trials with BF-200 ALA for mild-to-moderate AK.

40. Ameluz ${ }^{\circledR}$. Summary of Product Characteristics Ameluz ${ }^{\circledR}$ Biofrontera Bioscience GmbH, Leverkusen, Germany (2017).

41. Ameluz ${ }^{\circledR}$. US Prescribing Information. Biofrontera Bioscience GmbH, Leverkusen, Germany (2017).

42. Levulan ${ }^{\circledR}$ Kerastick ${ }^{\circledR}$. Prescribing information, $20 \%$ solution, DUSA Pharmaceuticals, Inc., MA, USA (2017).

43. Morton C, Szeimies RM, Sidoroff A et al. European Dermatology Forum Guidelines on topical photodynamic therapy. Eur. J. Dermatol. 25(4), 296-311 (2015).

44. Agostinis P, Berg K, Cengel KA et al. Photodynamic therapy of cancer: an update. CA Cancer J. Clin. 61(4), 250-281 (2011).

45. Ericson MB, Wennberg AM, Larko O. Review of photodynamic therapy in actinic keratosis and basal cell carcinoma. Ther. Clin. Risk Manag. 4(1), 1-9 (2008).

46. Kumar N, Warren CB. Photodynamic therapy for dermatologic conditions in the pediatric population: a literature review. Photodermatol. Photoimmunol. Photomed. 33(3), 125-134 (2017).

47. Cohen DK, Lee PK. Photodynamic therapy for non-melanoma skin cancers. Cancers (Basel) 8(10), pii:E98 (2016).

48. Soriano J, Mora-Espi I, Alea-Reyes ME et al. Cell death mechanisms in tumoral and non-tumoral human cell lines triggered by photodynamic treatments: apoptosis, necrosis and parthanatos. Sci. Rep. 7, 41340 (2017).

49. Peng Q, Berg K, Moan J, Kongshaug M, Nesland JM. 5-Aminolevulinic acid-based photodynamic therapy: principles and experimental research. Photochem. Photobiol. 65(2), 235-251 (1997).

50. Peng Q, Warloe T, Berg K et al. 5-Aminolevulinic acid-based photodynamic therapy. Clinical research and future challenges. Cancer 79(12), 2282-2308 (1997). 
51. Yang X, Palasuberniam P, Kraus D, Chen B. Aminolevulinic acid-based tumor detection and therapy: molecular mechanisms and strategies for enhancement. Int. J. Mol. Sci. 16(10), 25865-25880 (2015).

52. Navone NM, Polo CF, Frisardi AL, Andrade NE, Battle AM. Heme biosynthesis in human breast cancer-mimetic "in vitro" studies and some heme enzymic activity levels. Int. J. Biochem. 22(12), 1407-1411 (1990).

53. Schmitz L, Novak B, Hoeh AK, Luebbert H, Dirschka T. Epidermal penetration and protoporphyrin IX formation of two different 5-aminolevulinic acid formulations in ex vivo human skin. Photodiagnosis. Photodyn. Ther. 14, 40-46 (2016).

54. Kaliszewski M, Kwasny M, Kaminski J, Dabrowski Z, Burdziakowska E. The stability of 5-aminolevulinic acid and its ester derivatives. Acta. Pol. Pharm. 61(1), 15-19 (2004).

55. Bunke A, Zerbe O, Schmid H, Burmeister G, Merkle HP, Gander B. Degradation mechanism and stability of 5-aminolevulinic acid. J. Pharm. Sci. 89(10), 1335-1341 (2000).

56. Gaullier JM, Berg K, Peng Q et al. Use of 5-aminolevulinic acid esters to improve photodynamic therapy on cells in culture. Cancer Res. 57(8), 1481-1486 (1997).

57. Novak B, Schulten R, Lubbert H. Delta-aminolevulinic acid and its methyl ester induce the formation of Protoporphyrin IX in cultured sensory neurones. Naunyn Schmiedebergs Arch. Pharmacol. 384(6), 583-602 (2011).

58. Schulten R, Novak B, Schmitz B, Lubbert H. Comparison of the uptake of 5-aminolevulinic acid and its methyl ester in keratinocytes and skin. Naunyn Schmiedebergs Arch. Pharmacol. 385, 969-979 (2012).

59. Rodriguez L, Batlle A, Di Venosa G et al. Mechanisms of 5-aminolevulic acid ester uptake in mammalian cells. Br. J. Pharmacol. 147(7), 825-833 (2006).

60. Lange $\mathrm{N}$, Jichlinski P, Zellweger $\mathrm{M}$ et al. Photodetection of early human bladder cancer based on the fluorescence of 5-aminolaevulinic acid hexylester-induced protoporphyrin IX: a pilot study. Br. J. Cancer 80(1-2), 185-193 (1999).

61. Casas A, Batlle AM, Butler AR et al. Comparative effect of ALA derivatives on protoporphyrin IX production in human and rat skin organ cultures. Br. J. Cancer 80(10), 1525-1532 (1999).

62. Neittaanmaki-Perttu N, Gronroos M, Karppinen TT, Tani TT, Snellman E. Hexyl-5-aminolaevulinate $0.2 \%$ vs. methyl-5-aminolaevulinate $16 \%$ daylight photodynamic therapy for treatment of actinic keratoses: results of a randomized double-blinded pilot trial. Br. J. Dermatol. 174(2), 427-429 (2016).

63. Piacquadio DJ, Chen DM, Farber HF et al. Photodynamic therapy with aminolevulinic acid topical solution and visible blue light in the treatment of multiple actinic keratoses of the face and scalp: investigator-blinded, Phase 3, multicenter trials. Arch. Dermatol. 140(1), 41-46 (2004).

64. Maisch T, Santarelli F, Schreml S, Babilas P, Szeimies RM. Fluorescence induction of protoporphyrin IX by a new 5-aminolevulinic acid nanoemulsion used for photodynamic therapy in a full-thickness ex vivo skin model. Exp. Dermatol. 19(8), e302-e305 (2010).

-• Description and analysis of the epidermal penetration characteristics of BF-200 ALA compared with a methyl-aminolevulinic acid (MAL) formulation in a porcine ex vivo skin model.

65. Gadmar OB, Moan J, Scheie E, Ma LW, Peng Q. The stability of 5-aminolevulinic acid in solution. J. Photochem. Photobiol. B 67(3), 187-193 (2002).

66. Nissen CV, Philipsen PA, Wulf HC. Protoporphyrin IX formation after topical application of methyl aminolaevulinate and BF-200 aminolaevulinic acid declines with age. Br. J. Dermatol. 173(3), 760-766 (2015).

67. Nissen CV, Wiegell SR, Philipsen PA, Wulf HC. Short-term chemical pretreatment cannot replace curettage in photodynamic therapy. Photodermatol. Photoimmunol. Photomed. 32(3), 146-152 (2016).

68. Dirschka T, Radny P, Dominicus R et al. Photodynamic therapy with BF-200 ALA for the treatment of actinic keratosis: results of a multicentre, randomized, observer-blind Phase III study in comparison with a registered methyl-5-aminolaevulinate cream and placebo. Br. J. Dermatol. 166(1), 137-146 (2012).

- Head-to-head comparator study on Phase III level of the clinical efficacy and safety of BF-200 ALA compared with MAL in the treatment of AK.

69. Hofland HE, Bouwstra JA, Bodde HE, Spies F, Junginger HE. Interactions between liposomes and human stratum corneum in vitro: freeze fracture electron microscopical visualization and small angle x-ray scattering studies. Br. J. Dermatol. 132(6), 853-866 (1995).

70. Zellmer S, Pfeil W, Lasch J. Interaction of phosphatidylcholine liposomes with the human stratum corneum. Biochim. Biophys. Acta 1237(2), 176-182 (1995).

71. Golden GM, Mckie JE, Potts RO. Role of stratum corneum lipid fluidity in transdermal drug flux. J. Pharm. Sci. 76(1), 25-28 (1987).

72. Hirano S. A current overview of health effect research on nanoparticles. Environ. Health Prev. Med. 14(4), 223-225 (2009).

73. Moan J, Iani V, Ma LW. Choice of the proper wavelength for photochemotherapy. Prog. SPIE 2625, 544-549 (1996).

74. Opel DR, Hagstrom E, Pace AK et al. Light-emitting diodes: a brief review and clinical experience. J. Clin. Aesthet. Dermatol. 8(6), 36-44 (2015).

75. Wachowska M, Muchowicz A, Firczuk M et al. Aminolevulinic acid (ALA) as a prodrug in photodynamic therapy of cancer. Molecules 16, 4140-4164 (2011). 
76. Babilas $\mathrm{P}$, Kohl E, Maisch T et al. In vitro and in vivo comparison of two different light sources for topical photodynamic therapy. Br. J. Dermatol. 154(4), 712-718 (2006).

77. Juzeniene A, Juzenas P, Ma LW, Iani V, Moan J. Effectiveness of different light sources for 5-aminolevulinic acid photodynamic therapy. Lasers Med. Sci. 19(3), 139-149 (2004).

78. Szeimies RM, Radny P, Sebastian M et al. Photodynamic therapy with BF-200 ALA for the treatment of actinic keratosis: results of a prospective, randomized, double-blind, placebo-controlled Phase III study. Br. J. Dermatol. 163(2), 386-394 (2010).

- Placebo-controlled Phase III clinical trial to investigate the clinical efficacy and safety of BF-200 ALA in the treatment of AK using narrow and broad-spectrum lamps.

79. Novak B, Peteja M, Brueck T, Luebbert H. Potency of different red light sources in photodynamic induction of cell death in a squamous cell carcinoma cell line. Photodiagnosis Photodyn. Ther. 14, 128-130 (2016).

80. Reinhold U, Dirschka T, Ostendorf R et al. A randomized, double-blind, Phase III, multicentre study to evaluate the safety and efficacy of BF-200 ALA (Ameluz $((\mathrm{R})))$ vs. placebo in the field-directed treatment of mild-to-moderate actinic keratosis with photodynamic therapy (PDT) when using the BF-RhodoLED((R)) lamp. Br. J. Dermatol. 175(4), 696-705 (2016).

-. Placebo-controlled Phase III clinical trial to investigate the clinical efficacy and safety of BF-200 ALA in the treatment of field cancerization using narrow spectrum lamps.

81. Kohl E, Torezan LA, Landthaler M, Szeimies RM. Aesthetic effects of topical photodynamic therapy. J. Eur. Acad. Dermatol. Venereol. 24(11), 1261-1269 (2010).

82. Kim SK, Koo GB, Kim YS, Kim YC. Epithelial-mesenchymal interaction during photodynamic therapy-induced photorejuvenation. Arch. Dermatol. Res. 308(7), 493-501 (2016).

83. Touma D, Yaar M, Whitehead S, Konnikov N, Gilchrest BA. A trial of short incubation, broad-area photodynamic therapy for facial actinic keratoses and diffuse photodamage. Arch. Dermatol. 140(1), 33-40 (2004).

84. Karrer S, Kohl E, Feise K et al. Photodynamic therapy for skin rejuvenation: review and summary of the literature-results of a consensus conference of an expert group for aesthetic photodynamic therapy. J. Dtsch. Dermatol. Ges. 11(2), 137-148 (2013).

85. Szeimies RM, Lischner S, Philipp-Dormston W et al. Photodynamic therapy for skin rejuvenation: treatment options - results of a consensus conference of an expert group for aesthetic photodynamic therapy. J. Dtsch Dermatol. Ges. 11(7), 632-636 (2013).

86. Attili SK, Dawe R, Ibbotson S. A review of pain experienced during topical photodynamic therapy-our experience in Dundee. Photodiagnosis Photodyn. Ther. 8(1), 53-57 (2011).

87. Wang B, Shi L, Zhang YF et al. Gain with no pain? Pain management in dermatological photodynamic therapy. Br. J. Dermatol. 177(3), 656-665 (2017).

88. Warren CB, Karai LJ, Vidimos A, Maytin EV. Pain associated with aminolevulinic acid-photodynamic therapy of skin disease. J. Am. Acad. Dermatol. 61(6), 1033-1043 (2009).

89. BF-RhodoLED ${ }^{\circledR}$ User Manual Version 3.4-EN, Biofrontera Pharma GmbH. Europe: http://www.biofrontera.com/en/products-pipeline/products/rhodoled.html; US: http://www.biofrontera.us.com/for-healthcare-professionals/bf-rhodoled/

90. TrevioLux ${ }^{\circledR}$ Manual, MEDlight GmbH. https://www.medlight.eu/en/treviolux/

91. Fink C, Enk A, Gholam P. Photodynamic therapy - aspects of pain management. J. Dtsch Dermatol. Ges. 13(1), 15-22 (2015).

92. Wiegell SR, Haedersdal M, Philipsen PA, Eriksen P, Enk CD, Wulf HC. Continuous activation of PpIX by daylight is as effective as and less painful than conventional photodynamic therapy for actinic keratoses; a randomized, controlled, single-blinded study. $\mathrm{Br}$. J. Dermatol. 158(4), 740-746 (2008).

93. Wiegell SR, Haedersdal M, Eriksen P, Wulf HC. Photodynamic therapy of actinic keratoses with $8 \%$ and $16 \%$ methyl aminolaevulinate and home-based daylight exposure: a double-blinded randomized clinical trial. Br. J. Dermatol. 160(6), 1308-1314 (2009).

94. Wiegell SR, Fabricius S, Stender IM et al. A randomized, multicentre study of directed daylight exposure times of $1(1 / 2)$ vs. $2(1 / 2)$ h in daylight-mediated photodynamic therapy with methyl aminolaevulinate in patients with multiple thin actinic keratoses of the face and scalp. Br. J. Dermatol. 164(5), 1083-1090 (2011).

95. Wiegell SR, Fabricius S, Gniadecka M et al. Daylight-mediated photodynamic therapy of moderate to thick actinic keratoses of the face and scalp: a randomized multicentre study. Br. J. Dermatol. 166(6), 1327-1332 (2012).

96. Pottier R, Kennedy JC. Utilization of 5-aminolevulinic acid in the photodynamic therapy of tumors: biochemical and photobiological aspects. SPIE 2078, 129-138 (1994).

97. Wiegell SR, Wulf HC, Szeimies RM et al. Daylight photodynamic therapy for actinic keratosis: an international consensus: International Society for Photodynamic Therapy in Dermatology. J. Eur. Acad. Dermatol. Venereol. 26(6), 673-679 (2012).

98. Neittaanmaki-Perttu N, Karppinen TT, Gronroos M, Tani TT, Polonen I, Snellman E. Daylight photodynamic therapy for actinic keratoses: a randomized double-blinded non-sponsored prospective study comparing BF-200 aminolevulinic acid with methyl-5-aminolaevulinate. Br. J. Dermatol. 171(5), 1172-1180 (2014).

- The first ever clinical trial to investigate the efficacy and safety of BF-200 ALA compared with MAL in daylight-mediated photodynamic therapy for AK. 
99. Neittaanmaki-Perttu N, Gronroos M, Tani T, Snellman E. Long-term outcome of daylight photodynamic therapy with amino-5-laevulinate nanoemulsion vs. methyl-5-aminolaevulinate for actinic keratoses. Acta Derm. Venereol. 96(5), 712-713 (2016).

100. Wiegell SR, Fabricius S, Heydenreich J et al. Weather conditions and daylight-mediated photodynamic therapy: protoporphyrin IX-weighted daylight doses measured in six geographical locations. Br. J. Dermatol. 168(1), 186-191 (2013).

101. Kellner C, Bauriedl S, Hollstein S, Reinhold U. Simulated-daylight photodynamic therapy with BF-200 aminolaevulinic acid for actinic keratosis: assessment of the efficacy and tolerability in a retrospective study. Br. J. Dermatol. 172(4), 1146-1148 (2015). 